\title{
Assessment of Left Ventricular Function and Contractile Reserve in Patients with Hypertension
}

Kamal Ahmed Marghany, Abd-Elhamid Ismail Abu Rahhal, Abd-EIrahman Atef Shawkat

Department of Cardiology - Faculty of Medicine, Al-Azhar University

* Corresponding author: Abd-Elrahman Atef Shawkat, Mobile: (+20)01003152977, E-mail: abdou_shawkat@hotmail.com

\begin{abstract}
Background: Hypertension is a prevalent and well-recognized cardiovascular risk factor, which may lead to left ventricular (LV) systolic impairment through chronic pressure overload.
\end{abstract}

Aim of the work: An impaired contractile reserve (CR) may be an early manifestation of left ventricular (LV) systolic dysfunction in hypertensive patients. Using normotensive patients as controls, we examined LV CR and its correlates in hypertensive patients. Material and methods: The study was conducted prospectively on fifty cases. 30 cases (24 males and 6 females aged $55.57 \pm 10.07$ ) had hypertension. All patients were subjected to complete history taking including comorbidities, risk factors and full clinical examination. Patients with significant coronary or valvular disease, previous myocardial infarction or revascularization and diabetes were excluded. LV ejection fraction (LVEF) \& global longitudinal strain (GLS) were measured at rest and at low-dose dobutamine.

Results: Hypertensive patients, compared to control had significantly impaired GLS at rest $(-19.00 \pm 2.34 \%$ vs. -20.50 $\pm 1.52 \%, \mathrm{P}<0.015)$ and at low dobutamine dose $(-19.90 \pm 2.33 \%$ vs. $-22.60 \pm 1.88 \%, \mathrm{P}<0.001)$. Absolute and relative GLS CR were significantly lower in hypertensive patients $(-0.88 \pm 0.45 \%$ vs. $-2.12 \pm 0.77 \%$ and $4.70 \pm 2.76 \%$ vs. 10.33 $\pm 3.78 \%$, respectively, both $\mathrm{P}<0.001)$. Absolute and relative LVEF CR were significantly lower in hypertensive patients $(3.31 \pm 0.97 \%$ vs. $7.09 \pm 1.67 \%$ and $5.37 \pm 1.64 \%$ vs. $11.61 \pm 3.19 \%$, respectively, both $\mathrm{P}<0.001)$.

Conclusion: Compared to control, hypertensive patients with no other co-morbidities had impaired LV GLS at rest and impaired CR despite normal LVEF.

Keywords: Hypertension, Ventricular function, Contractile reserve, Echocardiography, Speckle tracking strain.

\section{INTRODUCTION}

Hypertension is a prevalent and wellrecognized cardiovascular risk, which may lead to left ventricular (LV) systolic impairment through chronic pressure overload. LV hypertrophy (LVH) is a compensatory process in response to increase wall stress. However, this initially useful adaptive mechanism later becomes 'a pathological change' in the myocardium. Whilst, LVH has been shown to be a powerful independent predictor for cardiovascular morbidity and mortality ${ }^{(\mathbf{1})}$.

Multiple recent studies have shown that LV ejection fraction (LVEF) lacks accuracy and sensitivity in detecting early subclinical impairment. In contrast, LV strain analysis has been proven to be more sensitive in the detection of early subclinical LV systolic dysfunction, when the LVEF is still within 'normal' limits ${ }^{(2)}$.

LV systolic dysfunction in the early stage can be subtle and sub-clinical where resting systolic function may remain preserved, but contractile reserve (CR) to inotropic stimulation may be blunted. A depressed CR has been documented in patients with aortic stenosis ${ }^{(3)}$, mitral regurge ${ }^{(4)}$, aortic regurge ${ }^{(5)}$ and in the diabetic cardiomyopathy ${ }^{\left({ }^{(6)}\right.}$ and is thought to represent an early manifestation of LV dysfunction. Similarly, impaired CR may be an early manifestation of LV systolic impairment in hypertensive patients.

\section{AIM OF THE WORK}

The aim of this study was to examine CR and its correlates in hypertensive patients and to examine the relationship between impaired $\mathrm{CR}$ and resting $\mathrm{LV}$ systolic function as assessed by LV deformation. A group of normotensive patients was recruited as controls.

\section{PATIENT AND METHODS}

This was a prospective observational study that was conducted from July 2018 to June 2019 and included 50 cases who presented to stress echocardiography test. 30 patients with hypertension as study group and twenty normotensive as control group. Complete history was taken (personal, past, present \& family) and complete physical examination (SBP, DBP, HR, RR, Temp \& BMI).

\section{Exclusion criteria:}

- Diabetes mellitus and moderate to severe left sided valvular diseases.

- Conduction abnormalities as well as pacemaker and ongoing arrhythmias.

- Congenital heart disease, poor echocardiographic window, previous myocardial infarction or coronary revascularisation.

The study protocol was approved by Al-Azhar University, Faculty of Medicine. A chart review was performed, and data were collected including patient demographics, medical history and physical examination.

Ethical consideration and written informed consent:

An approval of the study was obtained from AlAzhar University Academic and Ethical 
ejhm.journals.ekb.eg

Committee. Every patient signed an informed written consent for participation in the study.

Echocardiographic data were collected as follow:

A) Resting conventional 2D echocardiography included

(End-diastolic and end-systolic dimensions of the LV/

End-diastolic thickness of inter-ventricular septum and LV posterior wall /Ejection fraction).

B) Low dose dobutamine echocardiography was performed to all participants. Patients who were on Bblockers or non-dihydropyridine calcium blockers had their low-dose echocardiography assessment performed at $20 \mathrm{micg} / \mathrm{kg} / \mathrm{min}$. For the remaining patients, the low-dose assessment of them was performed at $10 \mathrm{micg} / \mathrm{kg} / \mathrm{min}$. These doses were chosen as they have been previously demonstrated to be safe and effective in detecting CR, without affecting heart rate, blood pressure (BP) or loading conditions (7).

C) 2D strain imaging by speckle tracking for deformation analysis: Endocardial borders was traced at the end-diastolic frame in apical four chamber view (AP4). End diastole will be defined by the QRS complex or as the frame after mitral valve closure. The software tracks speckles along the endocardial border throughout the cardiac cycle and peak global longitudinal strain (GLS) were measured automatically generating regional data from 6 segments and three cardiac cycles and were averaged. Normal resting peak global longitudinal strain (GLS) was defined as less than $-20 \%{ }^{(8)}$.

D) Assessment of Left Ventricular Contractile Reserve (LV CR): LVEF and strain analysis were performed both at rest and at low-dose dobutamine. CR was measured as the following: (1) Absolute CR was calculated as the difference in LVEF and GLS between the low-dose and their corresponding resting values. (2) Relative CR was defined as the ratio of absolute CR to the corresponding resting values and was expressed as percentage. Impaired CR was defined as an absolute $\mathrm{CR}$ of $<5 \%$ as measured by $\mathrm{LVEF}^{\left({ }^{(9)}\right.}$.

\section{Statistical methods}

Recorded data were analyzed using the statistical package for social sciences, version 20.0 (SPSS Inc., Chicago, Illinois, USA). Quantitative data were expressed as mean \pm standard deviation (SD). Qualitative data were expressed as frequency and percentage.

The following tests were done:

- Independent-samples t-test of significance was used when comparing between two means.

- Chi-square $\left(\mathrm{x}^{2}\right)$ test of significance was used in order to compare proportions between qualitative parameters.

- The confidence interval was set to $95 \%$ and the margin of error accepted was set to 5\%. So, the pvalue was considered significant as the following:

Probability (P-value)

- P-value $<0.05$ was considered significant.

- P-value $<0.001$ was considered as highly significant.

- P-value $>0.05$ was considered insignificant.

\section{RESULTS}

All patients were subjected to history taking and full clinical examination, resting 2D conventional echocardiography, low dose dobutamine echocardiography and 2D strain imaging by speckle tracking. All data were collected and tabled and statistically analyzed. The mean age was $55.57 \pm 10.07$ years and its p-value was 0.456 (ranged from 30-75 years). Males represented 24 patients (48\%) of the study population and the male to female ratio was (0.92: 1)

Table (1): Comparison between study group and control group concerning demographic data

\begin{tabular}{|c|c|c|c|c|c|}
\hline & Demographic data & Study group & Control group & $t / x 2 \#$ & p-value \\
\hline Age (years) & $\begin{array}{l}\text { Mean } \pm \text { SD } \\
\text { Range }\end{array}$ & $\begin{array}{l}55.57 \pm 10.07 \\
36-77\end{array}$ & $\begin{array}{l}53.20 \pm 12.06 \\
35-82\end{array}$ & 0.566 & 0.456 \\
\hline Sex & $\begin{array}{l}\text { Female } \\
\text { Male }\end{array}$ & $\begin{array}{l}16(53.3 \%) \\
14(46.7 \%)\end{array}$ & $\begin{array}{l}10(50.0 \%) \\
10(50.0 \%)\end{array}$ & 0.053\# & 0.817 \\
\hline
\end{tabular}

t-Independent Sample t-test; $\# x^{2}$ : Chi-square test p-value >0.05 NS

Table (2): Comparison between study group and control group regarding risk factors

\begin{tabular}{|c|c|c|c|c|c|}
\hline & Risk factors & Study group & Control group & X2 & p-value \\
\hline $\begin{array}{c}\text { Special } \\
\text { Habits }\end{array}$ & Absent & $24(\mathbf{8 0 . 0})$ & $\mathbf{1 4}(\mathbf{7 0 . 0 \%})$ & $\mathbf{0 . 6 5 8}$ & $\mathbf{0 . 4 1 7}$ \\
& Smoke & $\mathbf{6}(\mathbf{2 0 . 0 \%})$ & $\mathbf{6}(\mathbf{3 0 . 0 \%})$ & & \\
\hline Past History & HTN & $\mathbf{3 0}(\mathbf{1 0 0 . 0} \%)$ & $\mathbf{0}(\mathbf{0 . 0 \%})$ & $\mathbf{5 0 . 0 0 0}$ & $<\mathbf{0 . 0 0 1} * *$ \\
& Not HTN & $\mathbf{0}(\mathbf{0 . 0 \%})$ & $\mathbf{2 0}(\mathbf{1 0 0 . 0 \%})$ & & \\
\hline $\begin{array}{c}\text { Family } \\
\text { history }\end{array}$ & Negative & $13(43.3 \%)$ & $\mathbf{2 0}(\mathbf{1 0 0 . 0 \%})$ & $\mathbf{1 7 . 1 7 2}$ & $<\mathbf{0 . 0 0 1 * *}$ \\
& Positive & $17(56.7 \%)$ & $\mathbf{0}(\mathbf{0 . 0 \%})$ & & \\
\hline
\end{tabular}

t-Independent Sample t-test; \# $x^{2}$ : Chi-square test, $p$-value $>0.05 \mathrm{NS} ;{ }^{* *} p$-value $<0.001 \mathrm{HS}$. This table showed statistically significant difference between groups according to past history and family history and risk factors. 
ejhm.journals.ekb.eg

Table (3): Comparison between study group and control group as regards examinations

\begin{tabular}{|c|c|c|c|c|}
\hline Examinations & Study group & Control group & t-test & p-value \\
\hline $\begin{array}{l}\text { SBP } \\
\text { Mean } \pm \text { SD } \\
\text { Range } \\
\end{array}$ & $\begin{array}{l}132.50 \pm 6.12 \\
120-150\end{array}$ & $\begin{array}{l}120.50 \pm 7.76 \\
110-135\end{array}$ & 37.153 & $<0.001 * *$ \\
\hline $\begin{array}{l}\text { DBP } \\
\text { Mean } \pm \text { SD } \\
\text { Range }\end{array}$ & $\begin{array}{l}85.33 \pm 5.24 \\
80-100\end{array}$ & $\begin{array}{l}79.00 \pm 5.76 \\
70-90\end{array}$ & 16.194 & $<0.001 * *$ \\
\hline $\begin{array}{l}\text { HR } \\
\text { Mean } \pm \text { SD } \\
\text { Range }\end{array}$ & $\begin{array}{l}83.40 \pm 11.55 \\
68-115\end{array}$ & $\begin{array}{l}76.65 \pm 9.84 \\
56-102\end{array}$ & 4.598 & $0.037 *$ \\
\hline $\begin{array}{l}\text { RR } \\
\text { Mean } \pm \text { SD } \\
\text { Range } \\
\end{array}$ & $\begin{array}{l}16.90 \pm 1.03 \\
15-19\end{array}$ & $\begin{array}{l}16.60 \pm 1.05 \\
15-19\end{array}$ & 1.007 & 0.321 \\
\hline $\begin{array}{l}\text { Temp. } \\
\text { Mean } \pm \text { SD } \\
\text { Range }\end{array}$ & $\begin{array}{l}38.56 \pm 8.59 \\
35.5-84\end{array}$ & $\begin{array}{l}36.86 \pm 0.23 \\
36.5-37.2\end{array}$ & 0.781 & 0.381 \\
\hline $\begin{array}{l}\text { BMI }\left[w t /(h t)^{\wedge} 2\right] \\
\text { Mean } \pm \text { SD } \\
\text { Range }\end{array}$ & $\begin{array}{l}26.50 \pm 3.47 \\
22.5-34.8\end{array}$ & $\begin{array}{l}25.70 \pm 2.92 \\
22.5-32.5\end{array}$ & 0.719 & 0.401 \\
\hline
\end{tabular}

t-Independent Sample t-test

p-value $>0.05 \mathrm{NS} ; *$ p-value $<0.05 \mathrm{~S} ; * *$-value $<0.001 \mathrm{HS}$

This table showed statistically significant difference between groups according to SBP, DBP, HR, RR, Temp and BMI.

Table (4): Comparison between study group and control group according to IVSD, PWD, LVIDd, LVIDs, EF $\%$ and GLS\% at resting echocardiography

\begin{tabular}{|l|l|l|l|l|}
\hline $\begin{array}{l}\text { Resting } \\
\text { Echocardiography }\end{array}$ & Study group & Control group & t-test & p-value \\
\hline $\begin{array}{l}\text { IVSD } \\
\text { Mean } \pm \text { SD }\end{array}$ & $\begin{array}{l}\text { 1.18 } \pm 0.14 \\
\text { Range }\end{array}$ & $\begin{array}{l}0.90 \pm 0.17 \\
0.6-1.2\end{array}$ & 41.007 & $<0.001^{* *}$ \\
\hline $\begin{array}{l}\text { PWD } \\
\text { Mean } \pm \text { SD }\end{array}$ & $1.12 \pm 0.16$ & $0.89 \pm 0.15$ & 27.331 & $<0.001^{* *}$ \\
Range & $0.78-1.4$ & $0.7-1.23$ & & \\
\hline LVIDd & & & & \\
Mean \pm SD & $4.66 \pm 0.55$ & $4.83 \pm 0.46$ & 1.188 & 0.281 \\
Range & $3.58-5.81$ & $4.02-5.6$ & & \\
\hline LVIDs & $3.04 \pm 0.49$ & $3.13 \pm 0.40$ & 0.567 & 0.455 \\
$\begin{array}{l}\text { Mean } \pm \text { SD } \\
\text { Range }\end{array}$ & $1.99-4.15$ & $2.61-3.88$ & & \\
\hline EF \% & $61.34 \pm 4.57$ & $61.44 \pm 4.38$ & 0.006 & 0.937 \\
$\begin{array}{l}\text { Mean } \pm \text { SD } \\
\text { Range }\end{array}$ & $52.8-70.5$ & $53.5-70$ & & \\
\hline $\begin{array}{l}\text { GLS\% } \\
\text { Mean } \pm \text { SD }\end{array}$ & $-19.00 \pm 2.34$ & $-20.50 \pm 1.52$ & 6.397 & $0.015^{*}$ \\
\hline Range & $-22.8 \_-14$ & $-25.2-18.8$ & & \\
\hline
\end{tabular}

t-Independent Sample t-test;p-value >0.05 NS; *p-value <0.05 S; **p-value <0.001 HS

This table showed statistically significant difference between groups according to LVSD, PWD and GLS\%. 
Table (5): Comparison between study group and control group regarding EF\% and GLS\% at low dose dobutamine echocardiography

\begin{tabular}{|c|c|c|c|c|}
\hline Low Dose Echo & Study group & Control group & t-test & p-value \\
\hline \multicolumn{5}{|l|}{ EF \% : } \\
\hline Mean \pm SD & $64.35 \pm 4.93$ & $67.19 \pm 4.67$ & \multirow{2}{*}{6.398} & \multirow{2}{*}{0.053} \\
\hline Range & $55.2-74.5$ & 58-77.2 & & \\
\hline \multicolumn{5}{|l|}{ GLS \% : } \\
\hline Mean \pm SD & $-19.90 \pm 2.33$ & $-22.60 \pm 1.88$ & \multirow{2}{*}{18.508} & \multirow{2}{*}{$<0.001 * *$} \\
\hline Range & $-23.4 \_-15.1$ & $-28.5-20.2$ & & \\
\hline
\end{tabular}

$t$-Independent Sample t-test

p-value $>0.05 \mathrm{NS}$; *p-value $<0.05 \mathrm{~S}$; **p-value $<0.001 \mathrm{HS}$

This table showed statistically significant difference between groups as regards GLS\% at low dose echocardiography.

Table (6): Comparison between study group and control group according to absolute and relative EF\% and GLS at Left ventricular contractile reserve.

\begin{tabular}{|c|c|c|c|c|}
\hline LV CR & Study group & Control group & t-test & p-value \\
\hline $\begin{array}{l}\text { Absolute of EF \% } \\
\text { Mean } \pm \text { SD } \\
\text { Range }\end{array}$ & $\begin{array}{l}3.31 \pm 0.97 \\
1 \_5\end{array}$ & $\begin{array}{l}6.79 \pm 1.67 \\
4.5 \_11.2\end{array}$ & 85.563 & $<0.001 * *$ \\
\hline $\begin{array}{l}\text { Relative of EF (\%) } \\
\text { Mean } \pm \text { SD } \\
\text { Range } \\
\end{array}$ & $\begin{array}{l}5.37 \pm 1.64 \\
1.64 \_8.6\end{array}$ & $\begin{array}{l}10.61 \pm 3.19 \\
8 \_19.4\end{array}$ & 69.414 & $<0.001 * *$ \\
\hline $\begin{array}{l}\text { Absolute of GLS\% } \\
\text { Mean } \pm \text { SD } \\
\text { Range }\end{array}$ & $\begin{array}{l}-0.88 \pm 0.45 \\
-2 \_-0.2\end{array}$ & $\begin{array}{l}-2.12 \pm 0.77 \\
-4.1 \_-0.8\end{array}$ & 52.299 & $<0.001 * *$ \\
\hline $\begin{array}{l}\text { Relative of GLS (\%) } \\
\text { Mean } \pm \text { SD } \\
\text { Range }\end{array}$ & $\begin{array}{l}4.70 \pm 2.76 \\
0.96 \_14.2\end{array}$ & $\begin{array}{l}10.33 \pm 3.78 \\
4 \_21.2\end{array}$ & 37.043 & $<0.001 * *$ \\
\hline
\end{tabular}

t-Independent Sample t-test; **p-value <0.001 HS

This table showed highly statistically significant increased mean of control group compared to study group concerning absolute of EF, relative of EF (\%), absolute of GLS and relative of GLS (\%) of Left ventricular contractile reserve.

Table (7): Comparison between baseline and at low dose echocardiography regarding EF\% in each group

\begin{tabular}{|l|l|l|}
\hline EF\% & Study group & Control group \\
\hline Baseline & $61.34 \pm 4.57$ & $61.44 \pm 4.38$ \\
\hline Low Dose Echo & $64.35 \pm 4.93$ & $67.19 \pm 4.67$ \\
\hline Paired Sample t-test & 4.30 & 8.288 \\
\hline$p$-value & $0.021 *$ & $<0.001 * *$ \\
\hline
\end{tabular}

t-Paired Sample t-test; **p-value <0.001 HS

This table showed statistically significant increased mean of at low dose echocardiography compared to baseline according to $\mathrm{EF} \%$ in each group.

Table (8): Comparison between baseline and at low dose echo regarding GLS\% in each group

\begin{tabular}{|l|l|l|}
\hline GLS\% & Study group & Control group \\
\hline Baseline & $\mathbf{- 1 9 . 0 0} \pm \mathbf{2 . 3 4}$ & $\mathbf{- 2 0 . 5 0} \pm 1.52$ \\
\hline Low Dose Echo & $-\mathbf{1 9 . 9 0} \pm \mathbf{2 . 3 3}$ & $\mathbf{- 2 2 . 6 0} \pm \mathbf{1 . 8 8}$ \\
\hline Paired Sample t-test & $\mathbf{5 . 5 8}$ & $\mathbf{1 1 . 4 9 2}$ \\
\hline p-value & $\mathbf{0 . 0 0 8}$ & $<\mathbf{0 . 0 0 1} * *$ \\
\hline
\end{tabular}

t-Paired Sample t-test; **p-value <0.001 HS

This table showed statistically significant increased mean of low dose echo compared to baseline according to GLS\% in each group. 


\section{DISCUSSION}

In patients with treated hypertension without DM or significant ischemic heart disease, despite having normal LVEF at rest, subclinical LV systolic dysfunction was evident when assessed by GLS compared to normotensive patients. Furthermore, hypertensive patients had an impaired ability to augment LV contractility in response to inotropic stimulation by dobutamine, as evident by the impaired GLS at low-dose dobutamine and a reduced CR. GLS at rest and with low-dose dobutamine, and CR were correlated with LV wall thickness. In addition, GLS at rest and with low-dose dobutamine were correlated with prevailing systolic BP.

The aim of this study was to detect the impaired contractile reserve (CR) as an early manifestation of left ventricular (LV) systolic dysfunction in hypertensive patients comparing them with normotensive patients as control group by using low-dose dobutamine stress echocardiography \& 2D speckle tracking echo (2D-STE).

Mean \pm SD age between hypertensive group and normotensive group was $55.57 \pm 10.07$ vs. 53.20 \pm 12.06 years, respectively and its p-value was 0.456 ) ranged from 30-75 years. This is nearly concordant with Matle et al. ${ }^{\left({ }^{(10)}\right.}$ who discussed the role of speckle tracking echocardiography in assessing LV CR in hypertensive patients. They studied 129 cases with mean age of $60.0 \pm 8.7$ vs. $56.7 \pm 10.2$ years, respectively and its p-value was 0.051. Also, concordant with Narayanan et al. ${ }^{(11)}$ who discussed cardiac mechanics in mild hypertensive heart disease with Speckle-Strain Imaging Study. The mean age was $53 \pm 12$ vs. $49 \pm 13$, and its p-value was NS.

Males represented 24 patients $(48 \%$ of the study population) and the male to female ratio was (0.92: 1) and its p-value was 0.817 which is nearly concordant with Matle $\boldsymbol{e t ~ a l . ~}{ }^{\left({ }^{(10)}\right.}$ who represented 68 males (52\% of the study population) and the male to female ration (1.11: 1), whereas Narayanan et al. ${ }^{(11)}$ represented 73 males (70\% of study population) and the male to female ratio was $(2.3: 1)$.

Our study concluded presence of statistically significant difference between hypertensive and normotensive groups in the following predictor variables :

Our study revealed significant difference between hypertensive and normotensive groups in blood pressure. We revealed SBP of $132.50 \pm 6.12$ vs. $120.50 \pm 7.76$, respectively and its p-value was < 0.001 , which is nearly concordant with Matle $\boldsymbol{e t}$ al. (10) who revealed $143.9 \pm 16.3$ vs. $129.1 \pm 11.6$, respectively and its p-value was $<0.001$. We revealed DBP of $85.33 \pm 5.24$ vs. $79.00 \pm 5.76$, respectively and its p-value was <0.001, which is nearly concordant with Matle et al. ${ }^{(10)}$ who revealed $84.0 \pm$
12.7 vs. $80.1 \pm 8.6$ and its p-value was 0.034 and nearly concordant with Narayanan et al. ${ }^{(11)}$ who revealed SBP of $137 \pm 19$ vs. $118 \pm 13$, respectively and its p-value was $<0.001$ and revealed DBP of $82 \pm$ 10 vs. $73 \pm 8$, respectively and its p-value was $<0.001$.

Our study revealed significant difference between hypertensive and normotensive groups in heart rate. We revealed $83.40 \pm 11.55$ vs. $76.65 \pm$ 9.84 , respectively and its p-value was 0.037 , which is discordant with Matle $\boldsymbol{e t}$ al. ${ }^{(10)}$ who revealed $65.3 \pm$ 10.5 vs. $64.2 \pm 9.0$ and its p-value was 0.525 .

Our study revealed significant difference between hypertensive and normotensive groups in Inter-ventricular septum dimension (IVSd). We revealed $1.18 \pm 0.14$ vs. $0.90 \pm 0.17$, respectively and its $p$-value was $<0.001$, which is nearly concordant with Matle et al. ${ }^{(10)}$ who revealed $1.1 \pm 0.2$ vs. $1.0 \pm$ 0.2 and its p-value was 0.003 and nearly concordant with Narayanan et al. ${ }^{(11)}$ who revealed $1.1 \pm 0.2$ vs. $0.8 \pm 0.1$, respectively and its $p$-value was $<0.001$.

In our study, there was significantly significant difference between hypertensive and normotensive groups in posterior wall thickness (PWTd). We revealed $1.12 \pm 0.16$ vs. $0.89 \pm 0.15$ respectively and its p-value was $<0.001$, which is nearly concordant with Matle et al. ${ }^{\left({ }^{10)}\right.}$ who revealed $1.1 \pm 0.1$ vs. $1.0 \pm$ 0.2 , respectively and its p-value was 0.001 and nearly concordant with Narayanan $\boldsymbol{e t}$ al. ${ }^{(11)}$ who revealed $1.1 \pm 0.2$ vs. $0.8 \pm 0.1$ respectively and its $p$-value was $<0.001$.

In our study, there was significantly difference in LV GLS between hypertensive and normotensive groups at rest. We revealed $-19.00 \pm 2.34 \%$ vs. -20.50 $\pm 1.52 \%$ respectively and its p-value was 0.015 , which is nearly concordant with Matle et al. ${ }^{(10)}$ who revealed $-17.1 \pm 1.8 \%$ vs. $-19.4 \pm 1.5 \%$ respectively and its p-value was $<0.001$. Also nearly concordant with Imbalzano et al. ${ }^{(12)}$ who revealed significantly difference in LV GLS between hypertensive patients with normal geometry (No LVH) and normotensive groups $(-18 \pm 1.9 \%$ vs. $-20.4 \pm 2.5 \%$, respectively and its p-value was 0.02). And significant difference in LV GLS between hypertensive patients with abnormal geometry $(\mathrm{LVH})$ and normotensive groups $(-15.9 \pm 3.3 \%$ vs. $-20.4 \pm 2.5 \%$. respectively and its $\mathrm{p}$-value was $<0.001)$. Moreover, it is concordant with.

Kouzu et al. (13) who found significantly impaired longitudinal strain in the hypertensive group, (concentric, $-15.1 \pm 4.0 \%$, eccentric, $-15.9 \pm$ $4.4 \%$ vs. control $-18.9 \pm 3.3 \%$, its $\mathrm{P}$ value $<0.05$ ) with LVH being the only independent

In our study, there was significant difference in LV GLS between hypertensive and normotensive groups at low dose dobutamine infusion. We revealed $-19.90 \pm 2.33 \%$ vs. $-22.60 \pm 1.88 \%$ respectively and its p-value was $<0.001$, which is nearly concordant 
ejhm.journals.ekb.eg

with Matle et al. ${ }^{(10)}$ who revealed $-18.1 \pm 2.3 \%$ vs. $22.6 \pm 2.4 \%$, respectively and its $p$-value was $<0.001$. Moreover, numerous studies have found LVEF to be insensitive in detecting subclinical myocardial dysfunction in a variety of cardiovascular conditions, and only detects abnormalities in an advanced stage of hypertensive heart disease. In contrast, Drazner (14) discussed the progression of hypertensive heart disease and proved that strain analysis to be more sensitive and accurate in detecting subclinical myocardial dysfunction as mentioned above.

In our study, There was significantly impaired absolute GLS CR between hypertensive compared to normotensive group. We revealed $-0.88 \pm 0.45 \%$ vs. $-2.12 \pm 0.77 \%$, respectively and its p-value was < 0.001 , which is nearly concordant with Matle $\boldsymbol{e t} \boldsymbol{a l}$. (10) who revealed $-1.0 \pm 2.8 \%$ vs. $-3.2 \pm 2.2 \%$, respectively and its p-value was $<0.001$.

In our study, there was significantly impaired relative GLS CR between hypertensive compared to normotensive group. We revealed $4.70 \pm 2.76 \%$ vs. $10.33 \pm 3.78 \%$, respectively and its p-value was $<0.001$, which is nearly concordant with Matle $\boldsymbol{e t}$ al. (10) who revealed $5.0 \pm 5.6 \%$ vs. $16.4 \pm 11.7 \%$, respectively and its p-value was $<0.001$. Besides, Badran et al. ${ }^{\left({ }^{15}\right)}$ found significantly impaired reserve functional with exercise, in hypertensive patients compared to controls $(10 \pm 16 \%$ vs. $17 \pm 6 \%$, respectively and its p-value was $<0.001$ ).

Our study demonstrated that patients with hypertension had impaired CR when assessed by GLS but not by LVEF.

Tan et al. ${ }^{(16)}$ found significantly lower GLS in hypertensive patients both at rest and on exercise compared to healthy controls. the patients had reduced systolic longitudinal function (reserve index $0.97 \pm 1.34$ vs. $2.32 \pm 1.24$, respectively and its pvalue was 0.001 ). However, the hypertensive group in their study had a significantly higher body mass index compared to controls, and a significant percentage of patients $(20 \%)$ had a history of coronary artery disease and diabetes.

These co-morbidities and obesity have all been found to independently affect GLS and their results may therefore be confounded by these co-morbidities in the hypertensive group. In our study, both coronary artery disease and diabetes were excluded, our results would be more reflective of the true impact of hypertension on LV systolic deformation. Previous studies demonstrating impaired GLS in patients with hypertension used healthy subjects as controls. We used normotensive patients with comparable cardiovascular risk factors. Furthermore, we excluded patients with diabetes and significant coronary artery disease, and therefore were able to examine GLS in a more homogenous patient population, where the only major factor adversely affecting LV deformation was hypertension.
Our study concluded no statistically significant difference between hypertensive and normotensive groups in the following predictor variables:

No significant correlation between prevailing resting systolic or diastolic BP and LVEF and LV GLS, and there were no correlations between prevailing BP and CR measured by LVEF and LV GLS, which is nearly concordant with Matle et al. ${ }^{(10)}$.

Our study revealed no significant difference between hypertensive and normotensive groups in smoking [6 (20.0\%) vs.6 (30.0\%) respectively and its p-value was 0.417$]$, which is nearly concordant with Matle et al. ${ }^{(10)}$.

Our study revealed no significant difference between hypertensive and normotensive groups in Body Mass Index (BMI), which is nearly concordant with Matle et al. ${ }^{\left({ }^{10)}\right.}$ who revealed $29.0 \pm 4.4$ vs. 27.8 \pm 4.4 , respectively and its p-value was 0.128 .

Our study revealed no significant difference between hypertensive and normotensive groups in Left venticular internal dimensions (LVIDd) (sysolic $\&$ diastolic) that was $4.66 \pm 0.55$ vs.4.83 \pm 0.46 respectively and its p-value was 0.281 and LVIDs that was $3.04 \pm 0.49$ vs. $3.13 \pm 0.40$ respectively and its p-value was 0.455 , which is nearly concordant with Matle $\boldsymbol{e}$ al. ${ }^{(10)}$ who revealed LVIDd that was $4.6 \pm 0.5$ vs. $4.6 \pm 0.4$ respectively and its p-value was 0.9 and LVIDs that was $2.9 \pm 0.6$ vs. $2.6 \pm 0.4$, respectively and its p-value was 0.119 .

In our study, there was no significant difference in LVEF between hypertensive and normotensive groups at rest. We revealed $61.34 \pm 4.57 \%$ vs. 61.44 $\pm 4.38 \%$, respectively and its p-value was 0.937 , which is nearly concordant with Matle et al. ${ }^{(10)}$ who revealed $64.5 \pm 6.0 \%$ vs. $64.5 \mathrm{~b} \pm 6.6 \%$ respectively and its p-value was 0.986 , which is nearly concordant with Narayanan et al. ${ }^{(11)}$ who revealed $68 \pm 6 \%$ vs. $66 \pm 7 \%$, respectively and its p-value was NS.

In our study, there was no significant difference in LVEF between hypertensive and normotensive groups at low dose dobutamine infusion. We revealed $64.35 \pm 4.93 \%$ vs. $67.19 \pm 4.67 \%$, respectively and its p-value was 0.053 , which is nearly concordant with Matle $\boldsymbol{e t}$ al. ${ }^{\left({ }^{(10)}\right.}$ who revealed $72.1 \pm 6.5 \%$ vs. $71.2 \pm 7.0 \%$, respectively and its p-value was 0.424 .

\section{LIMITATIONS}

A Significant limitation is the relatively small sample size in our study. As the absence of ischemic heart diseases was a strict exclusion criterion. As diabetes mellitus and ischemic diseases are highly prevalent diseases among people, so a large number of screened cases had to be excluded. We believed that inclusion of these diseases would confound our results as these conditions have been shown to cause left ventricular systolic dysfunction. Nonetheless, compared to most of other published studies to assess left ventricular contractile reserve, our study had a 
strict exclusion criteria to avoid any expected potential confounders.

In our study, we only used the prevailing blood pressure, which was measured just prior to the commencement of the dobutamine stress echocardiography. This blood pressure reading may not reflect overall blood pressure control for the patient. Using blood pressure measurements of 24 hours ambulatory monitoring might be more reflective of the overall average blood pressure, but this was beyond the scope of our study.

In our study, B-blocker treatment may have negative inotropic effect and chronotropic effect on the left ventricle and its response to dobutamine. So we performed the low-dose dobutamine stress test at 20 $\mathrm{mic} / \mathrm{kg} / \mathrm{min}$ for patients on such treatment, as compared to $10 \mathrm{mic} / \mathrm{kg} / \mathrm{min}$ for cases who were not.

\section{CONCLUSION}

In patients with hypertension with no other comorbidities like diabetes mellitus or ischemic heart disease, with normal resting left ventricular EF not only have impaired left ventricular GLS at rest but also lack contractile reserve with low-dose dobutamine. The impaired contractile reserve was correlated to left ventricular wall thickness independent of prevailing blood pressures. Assessment of contractile reserve by GLS may have incremental value in early diagnosis and subclinical left ventricular systolic dysfunction in patients with hypertension.

\section{REFERENCES}

1. Nacif MS, Liu Y, Yao J et al. (2013): 3D left ventricular extracellular volume fraction by low-radiation dose cardiac CT: assessment of interstitial myocardial fibrosis. J Cardiovasc Comput Tomogr., 7: 51-7.

2. Morris DA, Otani K, Bekfani T et al. (2014): Multidirectional global left ventricular systolic function in normal subjects and global left ventricular systolic function in normal subjects and global left ventricular systolic function in normal subjects and hypertension: multicenter evaluation. J Am Soc Echocardiogr., 27: 493500.

3. Mahfouz RA, El Zayat A, Yousry A (2015): Left ventricular restrictive filling pattern andthe presence of contractile reserve in patients with low-flow /low-gradient severe aortic stenosis. Echocardiography, 32: 65-70.

4. Magne J, Mahjoub H, Dulgheru R et al. (2014): Left ventricular contractile reserve in asymptomatic primary mitral regurgitation. Eur Heart J., 35: 1608-16.
5. Park SJ, Enriquez-Sarano M, Song JE et al. (2013): Contractile reserve determined on exercise echocardiography in patients with severe aortic regurgitation. Circ J., 77: 2390-8.

6. Cadeddu C, Nocco S, Piano D et al. (2013): Early impairment of contractility reserve in patients with insulin resistance in comparison with healthy subjects. Cardiovasc Diabetol., 12: 66-69.

7. Leung M, Juergens CP, Lo ST et al. (2014): Evaluation of coronary micro-vascular function by left ventricular contractile reserve with low-dose dobutamine echocardiography. Euro Intervention, 9: 1202-9.

8. Lang RM, Badano LP, Mor-Avi V et al. (2015): Recommendations for cardiac chamber quantification by echocardiography in adults: an update from the American Society of Echocardiography and the European Association of Cardiovascular Imaging. European Heart J Cardiovasc Imaging, 16: 233-71.

9. Lancellotti P, Pellikka PA, Budts W et al. (2015): The clinical use of stress echocardiography in non-ischemic heart disease: recommendations from the European Association of Cardiovascular Imaging and the American Society of Echocardiography. Eur Heart J Cardiovasc Imaging, 17: 1191-229.

10. Matle JF, Thomas T, Leung DY (2018): Left ventricular function and contractile reserve in patients with hypertension. European Heart Journal Cardiovascular Imaging, 19 (11): 1253-1259.

11. Narayanan A, Aurigemma GP, Chinali $M$ et al. (2009): Cardiac mechanics in mild hypertensive heart disease: a speckle-strain imaging study. Circ Cardiovasc Imaging, 2: 382-90

12. Imbalzano E, Zito C, Carerj S et al. (2011): Left ventricular function in hypertension: new insight by speckle tracking echocardiography. Echocardiography, 28: 649-57.

13. Kouzu H, Yuda S, Muranaka A et al. (2011): Left ventricular hypertrophy causes different changes in longitudinal, radial, and circumferential mechanics in patients with hypertension: a two-dimensional speckle tracking study. J Am Soc Echocardiogr., 24: 192-9.

14. Drazner MH (2011): The progression of hypertensive heart disease. Circulation, 123: 327-34.

15. Badran HM, Faheem N, Ibrahim WA et al. (2013): Systolic function reserve using two-dimensional strain imaging in hypertrophic cardiomyopathy: comparison with essential hypertension. J Am Soc Echocardiogr., 26: 1397-406

16. Tan YT, Wenzelburger F, Lee E et al. (2010): Abnormal left ventricular function occurs on exercise in well-treated hypertensive subjects with normal resting echocardiography. Heart, 96: 948-53. 